\title{
Non-synonymous JAK Family Gene Mutation
}

National Cancer Institute

\section{Source}

National Cancer Institute. Non-synonymous JAK Family Gene Mutation. NCI Thesaurus.

Code C136641.

A point mutation in a gene that is a member of the JAK gene family that encodes an amino acid substitution in a JAK family protein. 